\title{
Gut Microbiota, Bacterial Translocation, and Interactions with Diet: Pathophysiological Links between Major Depressive Disorder and Non-Communicable Medical Comorbidities
}

\author{
Anastasiya Slyepchenko ${ }^{a} \quad$ Michael Maes $^{b-f} \quad$ Felice N. Jacka $^{\text {b }}$ g-i \\ Cristiano A. Köhlerj Tatiana Barichellok Roger S. Mclntyrel Michael Berk ${ }^{\mathrm{b}, \mathrm{m}}$ \\ Iria Grande ${ }^{\mathrm{n}}$ Jane A. Foster ${ }^{\circ}$ Eduard Vieta ${ }^{\mathrm{n}}$ André F. Carvalho ${ }^{\mathrm{j}}$ \\ a McMaster Integrative Neuroscience Discovery and Study (MiNDS), McMaster University, Hamilton, Ont., \\ Canada; ${ }^{b}$ Deakin University, IMPACT Strategic Research Centre, School of Medicine and Barwon Health, Geelong, \\ Vic., Australia; ' ${ }^{\circ}$ Department of Psychiatry, Faculty of Medicine, Chulalongkorn University, Bangkok, Thailand; \\ ${ }^{\mathrm{d}}$ Department of Psychiatry, Faculty of Medicine, State University of Londrina, Londrina, Brazil; ${ }^{\text {e }}$ Department of

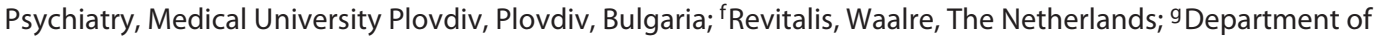 \\ Psychiatry, University of Melbourne, Parkville, Vic., ${ }^{\text {h} C e n t r e ~ f o r ~ A d o l e s c e n t ~ H e a l t h, ~ M u r d o c h ~ C h i l d r e n ' s ~ R e s e a r c h ~}$ \\ Institute, Melbourne, Vic., and 'Black Dog Institute, Sydney, N.S.W., Australia; 'Department of Clinical Medicine and \\ Translational Psychiatry Research Group, Faculty of Medicine, Federal University of Ceará, Fortaleza, Brazil; \\ kTranslational Psychiatry Program, Department of Psychiatry and Behavioral Sciences, McGovern Medical School, \\ The University of Texas Health Science Center at Houston (UTHealth), Houston, Tex., USA; 'Mood Disorder \\ Psychopharmacology Unit, University Health Network, Department of Psychiatry, University of Toronto, Toronto, \\ Ont., Canada; ${ }^{m}$ Orygen, The National Centre of Excellence in Youth Mental Health and Centre for Youth Mental \\ Health, Department of Psychiatry and Florey Institute for Neuroscience and Mental Health, University of Melbourne, \\ Parkville, Vic., Australia; ' Bipolar Disorder Unit, Institute of Neuroscience, Hospital Clinic, University of Barcelona, \\ IDIBAPS, CIBERSAM, Barcelona, Spain; ${ }^{\circ}$ Department of Psychiatry and Behavioural Neuroscience, McMaster \\ University, Brain-Body Institute, St. Joseph's Healthcare, Hamilton, Ont., Canada
}

\section{Key Words}

Mood disorders · Obesity · Depression · Diabetes .

Microbiota $\cdot$ Chronic fatigue syndrome $\cdot$ Inflammation .

Psychiatry $\cdot$ Irritable bowel syndrome $\cdot$ Oxidative stress

\section{Abstract \\ Background: Persistent low-grade immune-inflammatory processes, oxidative and nitrosative stress (O\&NS), and hy- pothalamic-pituitary-adrenal axis activation are integral to the pathophysiology of major depressive disorder (MDD). The microbiome, intestinal compositional changes, and re-}

sultant bacterial translocation add a new element to the bidirectional interactions of the gut-brain axis; new evidence implicates these pathways in the patho-aetiology of MDD. In addition, abnormalities in the gut-brain axis are associated with several chronic non-communicable disorders, which frequently co-occur in individuals with MDD, including but not limited to irritable bowel syndrome (IBS), chronic fatigue syndrome (CFS), obesity, and type 2 diabetes mellitus (T2DM). Methods: We searched the PubMed/MEDLINE database up until May 1, 2016 for studies which investigated intestinal dysbiosis and bacterial translocation (the 'leaky gut') in the pathophysiology of MDD and co-occurring somatic

\section{KARGER}

(C) 2016 S. Karger AG, Basel

E-Mail karger@karger.com

www.karger.com/pps
André F. Carvalho, $\mathrm{MD}, \mathrm{PhD}$

Department of Clinical Medicine, Faculty of Medicine

Federal University of Ceará, Rua Prof. Costa Mendes, 1608, $4^{\circ}$ andar

Fortaleza, CE 60430-040 (Brazil)

E-Mail andrefc7@terra.com.br 
comorbidities with an emphasis on IBS, CFS, obesity, and T2DM. Results: The composition of the gut microbiota is influenced by several genetic and environmental factors (e.g. diet). Several lines of evidence indicate that gut-microbiotadiet interactions play a significant pathophysiological role in MDD and related medical comorbidities. Gut dysbiosis and the leaky gut may influence several pathways implicated in the biology of MDD, including but not limited to immune activation, O\&NS, and neuroplasticity cascades. However, methodological inconsistencies and limitations limit comparisons across studies. Conclusions: Intestinal dysbiosis and the leaky gut may constitute a key pathophysiological link between MDD and its medical comorbidities. This emerging literature opens relevant preventative and therapeutic perspectives.

(c) 2016 S. Karger AG, Basel

\section{Introduction}

Persistent low-grade immune-inflammatory processes are an integral part of the pathophysiology of a substantial subset of patients with major depressive disorder (MDD) $[1,2]$. Among various immune-inflammatory marker elevations in MDD, meta-analytic evidence indicates that peripheral levels of interleukin (IL)-1 $\beta$, IL-6, $\mathrm{C}$-reactive protein (CRP), and soluble IL-2 receptor (sIL$2 \mathrm{R}$ ) are higher in individuals with MDD compared to healthy controls $[3,4]$. Integrative theoretical frameworks for MDD propose that environmental triggers such as psychosocial stress, sleep disruption, poor diet, physical inactivity, and smoking, together with medical factors such as autoimmune disorders and inflammatory medical conditions, activate neuroprogressive, low-grade inflammatory, oxidative and nitrosative stress (O\&NS) pathways [5-8]. The role of these systems in structural brain changes, cognitive deterioration, and treatment refractoriness in a subset of individuals has been thoroughly reviewed $[5,9]$. A recent addition to this literature is the emerging role of the microbiome and the possibility of microbiota-brain interactions being active in depression $[10,11]$. The microbiota-gut-brain axis, which includes both commensal and pathogenic bacteria in the gut, may influence behaviour in several ways, including but not limited to putative interactions with the vagus nerve, changes in central nervous system functioning, the enteric nervous system, brain plasticity [12], and the immune system $[13,14]$. In addition, experimental data indicate that the gut microbiota regulates blood-brain barrier permeability throughout life [15].The composition of microbiota in the intestine influences barrier integrity and an increase in gut permeability (also referred to as the 'leaky gut') and its role in the translocation of bacteria (and their products) into tissue [16]; this process has been implicated in the pathophysiology of MDD. Furthermore, this bacterial translocation is associated with several conditions that are frequently comorbid with MDD and are characterized by their psychosomatic symptoms, including irritable bowel syndrome (IBS) $[17,18]$, chronic fatigue syndrome (CFS) $[19,20]$, obesity, and type 2 diabetes mellitus (T2DM) [21-23].

Here, we review extant literature on the role of intestinal dysbiosis and the leaky gut in the pathophysiology of MDD and its medical comorbidities. In addition, resultant preventative and therapeutic perspectives are critically discussed.

\section{Search Strategy}

For this narrative review we searched the PubMed/ MEDLINE database up until May 1, 2016 for studies with the following search terms: 'gut dysbiosis', 'microbiota', 'leaky gut', 'probiotics', 'prebiotics' cross-referenced with 'depression', 'irritable bowel syndrome', 'chronic fatigue syndrome', 'type 2 diabetes' and 'obesity'. We included peer-reviewed original articles written in English that investigated microbiota dysbiosis and the leaky gut in $\mathrm{MDD}$ and related somatic comorbidities, namely CFS, IBS, obesity, and T2DM. In addition, clinical trials that investigated dietary interventions as well as prebiotics and probiotics as a treatment for MDD and these aforementioned comorbidities were considered.

\section{The Gut Microbiota}

In human adults, the intestinal microbiota consists of approximately 100 trillion organisms in a dynamic, symbiotic, mutualistic relationship with the host. This microbial community is very diverse, developing from the nearly sterile gut of a newborn to an adult composition, $90 \%$ of which is comprised of the phyla Bacteroidetes and Firmicutes [24]. Over 3.3 million genes are jointly encoded by the intestinal microbiota, with over 1,000 bacterial species identified as part of this ecosystem [24]. Advances in understanding the microbiome have in large been attributable to new methodologies in metagenomics, metatranscriptomics, proteomics, and metabolomics, each of which have been able to elucidate a portion of
Slyepchenko et al. 
host-microbiota interactions. However, in spite of largescale studies (e.g. the National Institutes of Health $\mathrm{Hu}$ man Microbiome Project, MyNewGut, the Canadian Microbiome Initiative, and the European MetaHIT initiative), much remains to be elucidated in characterizing a 'normal' microbiome in humans, its immune and biochemical functions, and the changes that occur in pathogenesis.

In addition, it is worthy to note that several limitations still hamper the comparability of findings across studies, which have been investigating changes in microbiota composition across disease states. These methodological inconsistencies include differences in methodology, variations in sample source, significant inter-individual differences, comorbidities, previous exposure to antibiotics, and potential confounders (e.g. differences in dietary habits), as well as differences in sample selection. Considering the heterogeneity in the clinical population with MDD and several of its co-morbid disorders, it is important to better understand how microbiota composition, diversity, and function might aid the stratification of individuals into different clinical subtypes.

A multitude of factors influence the composition of the microbiome. For instance, compelling data have indicated differences in the gut microbiota composition between babies born via Caesarean section versus natural birth $[25,26]$, while the microbiome of breast-fed infants differs from that of formula-fed babies [27, 28]. Diet shapes the composition of the gut microbiome throughout life [for review, see 29]. For example, in mice, a highfat diet was associated with a decrease in Bacteroidetes and an increase in both Firmicutes and Protebacteria [30, 31], although results have been conflicting [32]. In addition, a recent seminal study illustrates the influence of diet and exercise on microbiota diversity. In this study, protein consumption was associated with elevated microbial diversity (across 22 phyla), and athletes with a lower BMI had higher levels of Akkermansia, which has been inversely correlated with obesity in both mice [33] and humans [34]. Finally, a recent animal study has found, using a novel approach (multi-taxon insertion sequencing method), that the host genotype may influence dietmicrobiome interactions [35].

Insights into the role of the microbiome and its interactions with the host immune system have provided some details into its numerous functions in the human gut and at distant organs. Healthy gut microbiota contribute to normal intestinal homeostasis through immune signalling, for example, commensals can activate toll-like receptors (TLRs) in a manner that triggers heat shock pro-

Role of Intestinal Dysbiosis and 'Leaky Gut' in the Pathophysiology of MDD tein (member of a family of protective factors) - production by the host, thereby responding to disruptions in epithelial homeostasis and injury [36]. Importantly, certain gut microbiota produce short-chain fatty acids (ScFAs) like acetate, propionate, and butyrate, which are derived from the fermentation of undigested and unabsorbed carbohydrates. Butyrate modulates intestinal epithelial proliferation, apoptosis, and cell differentiation in the bowel, and also inhibits NF- $\kappa \mathrm{B}$, thus supporting mucosal barrier integrity $[37,38]$. ScFAs have neuroactive properties, while several classical neurotransmitters like GABA ( $\gamma$-aminobutyric acid) are also produced by the microbiota [39]. Microbiota also produce gasses such as hydrogen and ammonia, which are potentially neuroactive $[40,41]$. Whether or not these neuroactive chemicals are produced in sufficient quantity to extend beyond the local intestinal environment and influence the central nervous system is not yet clear. In the sections below, we overview evidence that gut compositional changes and intestinal inflammation related to a leaky gut may contribute to the pathophysiology of MDD and also to common non-communicable medical comorbidities. Here, we consider IBS, CFS, obesity, and T2DM as exemplars, although other non-communicable disorders such as cardiovascular disease and osteoporosis would probably be similarly impacted.

\section{Microbiota and Gut-Derived Inflammation in MDD}

The pathophysiology of MDD is typified by complex interactions with the following events in subsets of individuals: (1) increased low-grade inflammatory response, including raised peripheral levels of pro-inflammatory cytokines namely tumour necrosis factor- $\alpha$ (TNF- $\alpha$ ), IL- $1 \beta$, IL-6, sIL-2R, and CRP, an acute phase protein and inflammatory marker [3, 4]; (2) hypothalamic-pituitary-adrenal (HPA) axis dysregulation [42, 43]; (3) O\&NS, marked by an imbalance between systemic antioxidants and harmful reactive oxygen species (ROS) and reactive nitrogen species (RNS), which damage lipids, proteins, and nucleic acids [5], and (4) aberrations in cell-mediated immunity [9]. This cascade can have downstream detrimental effects on mitochondrial bioenergetics, which is of relevance to mood disorders as well as disorders such as CFS and diabetes [44]. These pathophysiological events appear to be influenced by perturbations in the equilibrium of the gut microbiota and by disruptions in the gut barrier.

A recent study has found that the microbiota of patients with MDD is significantly different compared to 
healthy controls and is characterized by a relative abundance of Firmicutes, Actinobacteria, and Bacteroidetes [10]. In addition, this study found that faecal transplantation of germ-free mice with microbiota from MDD patients but not from healthy controls led to depressive-like behavioural alterations, which appeared to be driven by disturbances of microbial genes and host metabolites involved in carbohydrate and amino acid metabolism [10]. Previous investigations have consistently observed microbiota compositional changes in patients with MDD compared to healthy controls, notwithstanding the fact that specific differences in microbial composition have varied across studies $[10,11,45]$. Online supplementary table S1 (see www.karger.com/doi/10.1159/000448957), which accompanies the online version of this article, presents differences in gut microbial composition observed in clinical studies of MDD compared to healthy controls. Linking specific bacterial to clinical phenotypes is a necessary step in order to better understand how to target microbiota in treatment and in drug development.

Evidence of increased bacterial translocation has now surfaced in the pathophysiology of depression, wherein bacterial translocation, marked by the serum presence of lipopolysaccharide (LPS)-respondent IgM and IgA has been observed [14]. LPS is a component of cell walls of Gram-negative bacteria. Cells of the gut mucosa are bound by tight junctions, which in homeostatic, healthy conditions provide a barrier between luminal bacteria from the interstitium. The disruption of tight junctions and barrier integrity may thus cause normally non-invasive bacteria to translocate to the mesenteric lymph nodes, the lamina propria, and the peripheral blood. In mesenteric lymph nodes and peripheral blood, the translocated Gram-negative bacteria and related bacterial products such as LPS may cause immune activation, binding to TLR-2/4 complexes and causing increased production of pro-inflammatory cytokines and ROS/ RNS $[46,47]$.

Heightened IgA and IgM-mediated immune responses to LPS from Hafnia alvei, Pseudomonas aeruginosa, Morganella morganii, Pseudomonas putida, Citrobacter koseri, and Klebsiella pneumoniae in MDD are consistent with increased bacterial translocation of gut microbiota due to a leaky gut [14]. Furthermore, disruptions in the gastrointestinal mucosa could then contribute to immune activation and O\&NS in the pathophysiology of MDD [48]. The administration of LPS to humans may affect mood and elevate anxiety, while increasing peripheral levels of several cytokines [49]. Indeed, the infusion of inflammatory cytokines is arguably good evidence that cytokines contribute to depression as depressive symptoms are observed clinically with the therapeutic administration of interferon [50, 51].

Changes in gut barrier function can occur as an effect of dysbiosis and immune-inflammatory responses, whereby permeability of the intestinal mucosa may be amplified, and bacteria, along with toxic compounds, translocate into the nearby capillaries [14]. The movement of Gram-negative bacteria into mesenteric lymph nodes and the bloodstream is particularly important to these pathogenic processes because this pathway may cause amplified immune-inflammatory responses. Further, Gram-negative bacteria translocation is linked to inflammatory mechanisms by a pathway induced by LPS (and other pathogen-associated molecular patterns) via the activation of TLR-2/4, which leads to the induction of immune mechanisms, ROS/RNS, and subsequent low-grade inflammation and activated O\&NS processes [52]. The latter in turn may produce redoxderived DAMPs (damage-associated molecular patterns), which further activate TLR-2/4 complexes, leading to a vicious cycle referred to as the TLR-2/4 radical cycle [52], which has been proposed to be a major driver of chronic immune activation and O\&NS processes in several neuro-immune disorders. Immune activation can include the synthesis of TNF- $\alpha$ [53] and the activation of NF- $\kappa B$ and MAPK, which trigger the production of pro-inflammatory cytokines and result in gut-derived systemic inflammation [54]. Immune-inflammatory responses also include the production of inflammatory mediators such as antibacterial lysozyme, an inflammatory mediator secreted by monocytes $[55,56]$. Inflammation may contribute to the translocation of commensal bacteria via transcytotic pathways. The translocation of Gram-negative bacteria from the gut has been linked to rising levels of O\&NS and autoimmune responses secondary to O\&NS, including peroxides and antibodies against oxidized LDL and IgM-mediated autoimmune responses to malondialdehyde, azelaic acid, phophatidyl inositol, nitro-tryptophan, and nitro-tyrosine in individuals with MDD [57]. Pro-inflammatory cytokines can also disrupt tight junctions, aiding these translocating processes [58]. In addition, LPS can enhance the expression of inducible nitric oxide (NO) synthase, which triggers the formation of $\mathrm{NO}$ by macrophages through a process involving IFN- $\gamma$ activation [53, 59]. LPS also stimulates nicotinamide adenine dinucleotide phosphate-oxidase, which generates ROS and inflammatory markers, including superoxide, peroxide, cyclooxygenase- 2 expression, and NF- $\kappa \mathrm{B}$ activation [55, 60-62]. Mi-
Slyepchenko et al. 


\section{Microbiota-gut-brain axis}

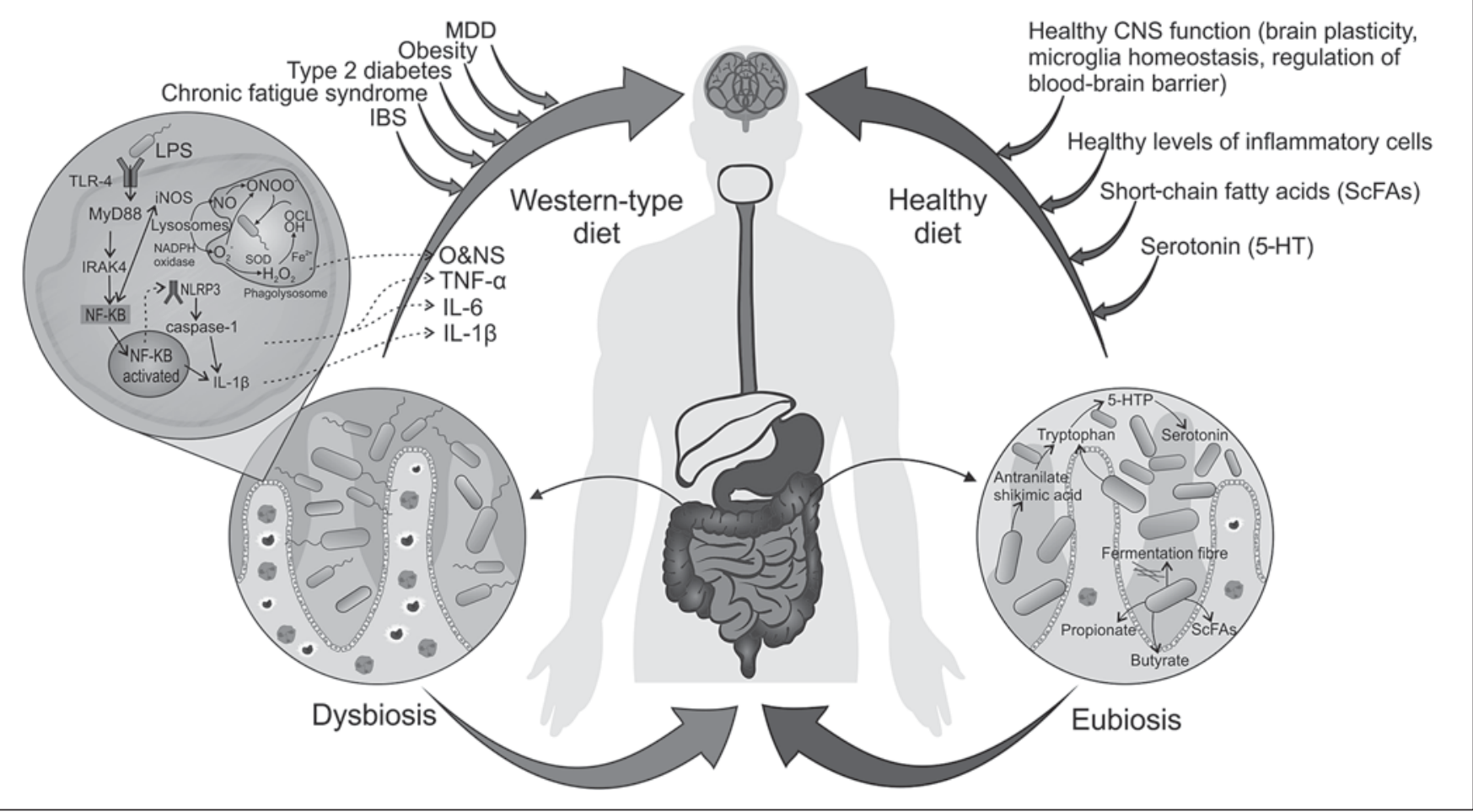

Fig. 1. Gut dysbiosis disrupts tight junctions of the gut epithelia, leading to bacterial translocation. LPS from the wall of Gram-negative bacteria is recognized by pattern recognition receptors (e.g. TLR-4); this activates a signalling pathway relayed by myeloid differentiation protein 88 (MyD88), which recruits the IL-1 receptorassociated kinase (IRAK-1), which is activated via phosphorylation and associated with TNF receptor-associated factor 6 (TRAF6), driving the activation of NF- $\kappa \mathrm{B}$ and the production of inflammatory cytokines by macrophages and other immune cells

croglia, when activated by LPS, synthesize ROS, which initiate oxidative processes to proteins and may lead to proteolysis [63].

LPS injections in experimental animals led to increased levels of malondialdehyde, nitrite, and nitrate and reduced levels of glutathione within the brain - the latter finding evident across many psychiatric disorders [64, 65]. Furthermore, the administration of antioxidants such as quercetin reduce LPS-induced O\&NS [66], indicating the reversible nature of these processes. O\&NS processes exacerbate disruptions in tight junction integrity in the gut, further driving gut-derived inflammation in a vicious cycle [67]. Thus, bacterial translocation from

Role of Intestinal Dysbiosis and 'Leaky

Gut' in the Pathophysiology of MDD (e.g. TNF- $\alpha$, IL-1 $\beta$, and IL-6). In addition, LPS activates inducible NO synthase and NADPH oxidase, leading to O\&NS. LPS also activates the microglia and disrupts the blood-brain barrier. These pathophysiological events are shared to some extent between MDD and related somatic comorbidities such as IBS, CFS, obesity, and T2DM. Conversely, a healthy microbiota produces several neuroactive mediators, including serotonin (5-HT) and ScFAs such as butyrate, which may aid in the maintenance of an intact gut barrier.

the gut may play a role in O\&NS among individuals with MDD. In addition, bacterial translocation may trigger the generation of neo-antigenic determinants in patients with MDD, thereby contributing to the propensity towards autoimmunity observed in this illness $[57,68]$.

\section{Gut Dysbiosis and Bacterial Translocation as a Link between MDD and Its Medical Comorbidities}

Many of the aforementioned pathways appear to be involved in the pathophysiology of somatic diseases that frequently co-occur in patients with MDD. Further, some 
medical comorbidities of MDD exhibit disruptions in intestinal barrier integrity and microbiota composition and express O\&NS and immune-inflammatory aberrations. Figure 1 provides a wide-angle lens view of these pathoetiological interactions.

\section{Irritable Bowel Syndrome}

IBS is the paradigmatic disorder of the brain-gut axis, presenting with abdominal pain and discomfort as well as alterations in bowel habits [69, 70]. IBS is associated with significant deficits in psychosocial function and impaired quality of life [71]. While its specific pathophysiology is currently unknown, gut-brain axis dysfunction has been implicated [72]. IBS is highly comorbid with MDD, with up to $30 \%$ of IBS patients presenting a diagnosis of MDD, while psychosocial variables appear to predispose individuals to IBS [73]. Patients with comorbid IBS and MDD are less likely to respond to treatment with either psychotherapy or antidepressants $[74,75]$.

Similarly to MDD, increased gut permeability has been noted in IBS $[76,77]$. Histological changes in IBS include upregulation of intraepithelial lymphocytes, lamina propria CD3+ and CD25+ cells, and neutrophils and mast cells [78]. In addition to immune cell activation in the distal bowel, peripheral low-grade inflammation appears to play a major role in the pathophysiology of IBS. Furthermore, evidence of chronic gut dysbiosis in IBS is substantial, which maylead to changes in gut motility and nociception [79]. Microbiota composition is distinctively different between those with IBS and healthy controls, characterized by a 2:1 ratio of Firmicutes to Bacteroidetes, an increase in Dorea sp., Ruminococcus sp., and Clostridium spp., and a decrease of Bifidobacterium sp. and Faecalibacterium sp. [80], consistent with findings of composition studies in MDD (suppl. table S1). Mast cells that are upregulated in IBS appear to have a higher expression of inducible NO synthase, an enzyme that produces large amounts of NO. Further, levels of IL- $1 \beta$ are upregulated in IBS, where NO may also drive the production of numerous cytokines, including IL-1 $\beta$, IL-1, IL-13, TNF- $\alpha$, and monocyte chemotactic protein-1, sustaining the inflammation observed in IBS [81]. Increased peripheral levels of cytokines in IBS, including IL-6, TNF- $\alpha$, and IL- $1 \beta$ [82], overlap with the cytokine profile seen in MDD. Moreover, exaggerated HPA axis activity in both IBS and MDD add to the overlapping pathophysiology of these disorders [83-85].

Evidence of bacterial translocation in IBS is also provided by higher peripheral levels of LPS as well as higher concentrations of anti-flagellin antibodies [86]. Moreover, Escherichia coli LPS-induced IL-6 secretion is ele- vated in IBS, indicating an enhanced response against Gram-negative bacteria in this disorder [82]. Changes in cell-mediated immunity may additionally contribute to the pathophysiology of IBS. For instance, Th1, Th2, Treg, and $B$ cells are key elements in the progression of IBS [87, 88]. Critically, the probiotic administration in IBS reduces levels of pro-inflammatory cytokines and T-cell function and preserves the integrity of the gut mucosa [8991]. This reconciliation of intestinal dysbiosis by probiotic treatment, which is associated with improved gut integrity, immune function, and IBS symptoms, suggests that the underlying cause of this disorder may be rooted in intestinal dysbiosis and its consequences, including the leaky gut. Bacterial products interact with TLRs and nucleotide oligomerization domain receptors, further driving mucosal immune activation [92].

\section{Chronic Fatigue Syndrome}

CFS is a disorder characterized by persistent and unexplained fatigue that is worsened by physical and mental exertion. Psychosocial factors play a role in CFS, which is frequently diagnostically comorbid with and difficult to disentangle from MDD [93, 94]. MDD is thus highly prevalent among those with CFS and involves overlapping symptomatology [95].

Several shared pathophysiological mechanisms can explain the associations between CFS and MDD. There is a growing body of literature describing immune dysfunction in CFS [96, 97]. 'Flu-like' symptoms and virus and bacterial infections frequently precede CFS [98]. In addition, higher peripheral levels of IL-1, IL-6, and TNF- $\alpha$ are also observed in CFS patients compared to healthy controls [20, 98]. Finally, CFS (like depression) is accompanied by mitochondrial dysfunction [99] and increased O\&NS $[100,101]$, which play a key role in CFS.

Evidence of changes in gut permeability and resultant bacterial translocation as a source of shared pathophysiology of CFS and MDD comes from observed IgA and IgM responses against LPS from enteric bacteria, including $H$. alvei, $P$. aeruginosa, $M$. morganii, $P$. mirabilis, $P$. putida, C. koseri, and K. pneumoniae [102]. In addition, IgA responses to LPS are linked to increased levels of IL1 , TNF- $\alpha$, and neopterin [103]. Furthermore, changes in microbiota composition have been noted in CFS; for instance, levels of Dialister appear to be decreased in CFS [104], similarly to findings observed in samples with MDD [11], whereas levels of Alistipes are increased in both diseases, though less consistently so in MDD $[11,45$, 105]. It is noteworthy that CFS frequently co-occurs with IBS, and gut inflammation and endotoxemia may play a DOI: $10.1159 / 000448957$
Slyepchenko et al. 
patho-etiological role in both diseases [100, 106, 107]. Similarly to MDD, CFS is characterized by a propensity towards O\&NS-induced autoimmune responses [108].

Furthermore, CFS is accompanied by inducible NO synthase activation and peripheral markers of O\&NS like thiobarbituric acid reactive substances (indicative of lipid peroxidation) and oxidized LDL [100, 109]. As in MDD, antioxidant levels are diminished in CFS, including zinc and dehydroepiendrosterone sulphate $[110,111]$. Immune reactivity indexed by IgM antibodies against fatty acids, including oleic, palmitic, and myristic acid, malondialdehyde, and phosphatidyl-inositol, is also observed in CFS; these are by-products of oxidative damage to lipids [110]. Antibodies against nitrogen monoxide derivatives, including nitro-tyrosine, nitro-phenyl-alanine, nitrotryptophan, and other nitrosative stress markers are also seen [110]. Finally, LPS induces an exaggerated production of TNF- $\alpha$ and IL- 6 in CFS patients, further strengthening the evidence for an association of CFS with disruptions in the intestinal mucosa and resultant bacterial translocation [112].

\section{Obesity and Type 2 Diabetes}

There is a vast pathophysiological overlap between obesity, T2DM, and depression, with bidirectional relationships being consistently reported $[113,114]$. These disorders also share common risk factors such as poor diet and physical inactivity $[115,116]$. In addition, these epidemiological associations are further illustrated by the recent proposal of a distinct metabolic-mood syndrome, characterized by changes in mood and metabolism after chronic stress exposure, and possibly cognitive dysfunction [117]. These conditions have been consistently related to immune activation and aberrations in HPA axis function [118-120].

Obesity, T2DM, and MDD share increased peripheral levels of cytokines like IL- 6 , TNF- $\alpha$, and IL- $1 \beta[1,121,122]$. Type 2 diabetes and obesity are also marked by higher concentrations of acute-phase proteins such as CRP, plasminogen activator inhibitor, and serum amyloid A [123-126]. Furthermore, increased peripheral levels of CRP, IL- 6 , and IL-1 $\beta$ levels may predispose individuals to T2DM [127, 128]. Obesity predispose immune cells towards a Th17 cell profile [126], and T2DM patients also have a skewed balance of Treg to Th17 cells and Treg to Th1 cells [129], a finding that has also been observed in MDD [130]. It is worth noting that the infiltration of abdominal adipose tissue by macrophages and other immune cells may play a significant role in the patho-aetiology of T2DM and obesity, driving the production of adipokines [131, 132].

Role of Intestinal Dysbiosis and 'Leaky Gut' in the Pathophysiology of MDD
A number of O\&NS pathways are activated in both T2DM and obesity. For instance, in T2DM the activation of NADPH oxidase, NO synthase, and oxidative phosphorylation may contribute to the production of ROS and RNS [133]. Hence, several oxidative stress markers appear elevated in T2DM, including but not limited to an increased ratio of GSH to glutathione levels, nitrotyrosine, S-glutathionylated proteins, advanced glycoxidation end products, and F2-isoprostane levels [134]. In obesity, elevated F2-isoprostane, malondialdhyde, and thiobarbituric acid reactive substance (a marker of lipid peroxidation) are observed [135]. Antioxidant levels, including vitamins $\mathrm{E}$ and $\mathrm{C}$, are reduced in T2DM [136], while in obesity, the total antioxidant capacity is decreased [135].

Intestinal dysbiosis also appears to be involved in the patho-aetiology of obesity and T2DM [32]. In addition, increased peripheral levels of LPS are observed in individuals with T2DM, and this endotoxemia may contribute to adipose tissue inflammation via the activation of TLRs $[137,138]$. Furthermore, the role of inflammation induced by Gram-negative bacteria in T2DM is evidenced by the fact that human abdominal adipocyte induction with LPS leads to enhanced IL- 6 and TNF- $\alpha$ production [137]. The precise alterations in microbiota composition in T2DM have varied across studies [32], although a large Scandinavian cohort has found a higher frequency of butyrate-producing bacteria (Roseburia intestinalis and Faecalibacterium prausnitzii) among postmenopausal women with T2DM compared to women with impaired glucose tolerance [139] (suppl. table S1). Butyrate contributes to the homeostasis and survival of colonocytes (see above), and thus these alterations may contribute to abnormalities in the gut barrier.

Higher peripheral levels of LPS in obese compared to lean individuals have also been demonstrated [140]. In addition, $4 \mathrm{~h}$ after the ingestion of a high-fat diet, obese individuals displayed higher peripheral increments in LPS compared to healthy controls [141]. Evidence from both animal and human research has consistently demonstrated that obesity is associated with microbiota dysbiosis [141].

A recent fascinating study illustrated the role of the microbiota in the patho-aetiology of obesity. In a cohort of female twins discordant for obesity, the transplantation of germ-free mice with an 'obese microbiota' transmitted an increase in total body and fat mass. Furthermore, co-housing humanized mice with the 'obese microbiota' with mice transplanted with a 'lean microbiota' prevented the development of obesity; the invasion of 
specific members of the Bacteriodetes phylum derived from the 'lean microbiota' prevented the development of obesity in co-housed mice transplanted with the 'obese microbiota' [142]. In addition, microbiota invasion and phenotypic change in mice transplanted with an obesogenic microbiota was dependent on dietary fibre and fat content [142]. Thus, diet and environment may interact with the gut microbiota to drive the progression of different metabolic phenotypes.

\section{Mechanistic Insights into Microbiota Changes in MDD and Its Comorbidities}

Recent studies have started to elucidate putative mechanisms underlying changes in the composition of microbiota as a pathophysiological aspect of MDD and related comorbidities. For instance, changes in phylum-level composition or the presence of particular species such as a decrease in Bacteroidetes (observed in MDD) [10, 143], IBS [80], obesity [144], impaired glucose tolerance [145], and CFS [105] could represent a consistent finding across these disorders. Nevertheless, another study found an increase in Bacteroidetes MDD patients [11], rendering these findings not entirely consistent.

Specific pathogenetic mechanisms of members of different genera of intestinal microbes have recently emerged. For example, an increased abundance of the Clostridium XIVB cluster is associated with decreases in serum levels of BDNF [11], a plasticity-associated neurotrophic factor whose peripheral levels appear to be decreased in MDD [146], and has also been implicated in the pathophysiology of IBS [147], CFS [148], and obesity [149].

Furthermore, Faecalibacterium - a genus of the Ruminococcaeceae family and an abundant commensal (approx. $5 \%$ in humans) - was found to be decreased in the faecal microbiota of MDD patients compared to healthy controls [11], while Faecalibacterium spp. are lowered by 1.5 in faecal samples of individuals with IBS in comparison to controls [80]. the presence of Faecalibacterium bacteria within the gastrointestinal tract is linked to antiinflammatory activities. For instance, F. prausnitzii downregulates the synthesis of the pro-inflammatory cytokines IL-12 and IFN- $\gamma$ and increases production of IL10 by mononuclear cells. The effects of $F$. prausnitzii can be in part attributable to the termination of NF- $\mathrm{kB}$ signalling and IL-8 synthesis [150]. F. prausnitzii is additionally associated with the fermentation of digestion-resistant carbohydrates into ScFAs, including butyrate, formate, and lactate [151]. Numerous taxa (e.g. Roseburia spp., Bacteroides spp. $[152,153])$ are associated with the production of butyrate, which may have beneficial functions, including but not limited to an increment in mucin synthesis, a decrease of bacterial translocation across the intestinal barrier, and the maintenance of the integrity of tight junctions within the intestinal epithelium in addition to the intrinsic signalling properties of ScFAs [154, 155]. ScFAs may additionally contribute to endocrine signalling through their effects on hormones such as glucagon-like peptide-1 (GLP-1), which are closely linked to metabolic disorders [156]. A number of taxa, disruptions of which are common in MDD, IBS, CFS, and metabolic disorders, are also linked to bile acid metabolism [157]. Bile acids can induce ONS and damage [158], which can disrupt the intestinal barrier [159-161].

A higher abundance of Alistipes in MDD [11, 143] may lead to changes in tryptophan levels, as Alistipes species are able to convert tryptophan to indole [162] and subsequently serotonin availability within the intestine, as tryptophan is its precursor. Such increases in Alistipes taxa have been additionally linked to gut inflammation and to abdominal pain in IBS [163], and have additionally been found to be elevated in patients with CFS [105]. Dietary changes, particularly animal-based diets, can further elevate Alistipes bacteria in the gastrointestinal tract [164]. Differences in the abundance of several bacterial taxa have been observed in MDD, including but not limited to Enterobacteriaceae, Erysipelotrichaceae spp., and Prevotellaceae. These bacteria may promote both mucosal and systemic immune activation [46, 57, 165-169] through mechanisms including an increase in intestinal permeability and the presence of inflammogenic flagellin components in particular.

Notwithstanding that several microbiota-mediated pathophysiological mechanisms could be involved in MDD, many of these have yet to be thoroughly investigated. Online supplementary table S1 outlines overlaps in microbiota composition at the level of phyla, family, and genera, which have been reported across studies in individuals with MDD, IBS, CFS, obesity, and T2DM, as well as putative pathophysiological mechanisms related to specific bacteria.

\section{Clinical Implications}

\section{Probiotics}

The term probiotics refers to live microorganisms that, when administered to adequate amounts, confer a health benefit to the host' [170]. The idea of treating psy-
38

Psychother Psychosom 2017;86:31-46 DOI: $10.1159 / 000448957$
Slyepchenko et al. 
chiatric disorders with probiotics is not new; in $1910 \mathrm{Dr}$. George Porter Phillips reported that although Lactobacillus tablets and powder were ineffective, a gelatin-whey formula comprised of lactic-acid-producing bacteria improved depressive symptoms in melancholic adults [171]. Preclinical studies and clinical trials have increasingly investigated a role for probiotics in the treatment of depressive-like behaviours [for an extensive review, see 172]. Several studies have demonstrated effects of probiotics in healthy volunteers; however, the benefit of these changes is not yet clear. For example, orally consumed Lactobacillus casei milk had no significant mood-elevating effects in healthy volunteers, while also impacting two measures of memory [173]. A recent randomized controlled trial (RCT) found that a multispecies probiotic composed of Bifidobacterium bifidum W23, Bifidobacterium lactis W52, Lactobacillus acidophilus W37, Lactobacillus brevis W63, L. casei W56, Lactobacillus salivarius W24, and Lactococcus lactis (W19 and W58) reduced cognitive reactivity to sad mood via a reduction in rumination and aggressive thoughts in healthy individuals [174]. This small RCT provided a proof of concept for probiotic supplementation as a potential preventative strategy for MDD.

A recent systematic review and meta-analysis of 15 RCTs on the use of probiotics for IBS [175] found that although probiotics varied in strain composition, these compounds reduced abdominal pain after 8 and 10 weeks of treatment. Furthermore, probiotics improved the severity of IBS symptoms, although not significantly compared to placebo [175], providing preface to probiotics as a conjunctive treatment for both disorders.

The treatment of individuals meeting formal criteria for CFS with the L. casei strain Shirota resulted in significant improvements in anxiety symptoms; these beneficial effects on anxiety correlated with an increase in Lactobacillus and Bifidobacteria in those taking the L. casei strain Shirota [176]. The finding of a rise in Bifidobacteria was significant considering that levels of this microorganism could be low in CFS [106]. In addition, preclinical data suggest that Bifidobacteria may contribute to the maintenance of gut barrier integrity (thus preventing endotoxemia) [177].

The therapeutic potential of probiotics for the management of obesity and T2DM has been extensively reviewed elsewhere [32, 178]. A recent meta-analysis found that treatment with probiotics (especially when composed by multiple strains) led to a reduction in several cardiovascular risk factors, including total cholesterol, LDL cholesterol, BMI, waist circumference, and inflammatory markers, compared to placebo [179]. ScFAs (e.g.

Role of Intestinal Dysbiosis and 'Leaky

Gut' in the Pathophysiology of MDD butyrate) appear to be a promising target for the probiotic treatment of T2DM; SCFAs bind to G-protein-coupled receptors, namely GPR41 and GPR43 [180, 181], to influence the host enteroendocrine system, driving the synthesis of proglucagon, GLP-1, peptide YY, and leptin [32]. Interestingly, GLP-1 analogues are effective approved treatments for T2DM [182], and preclinical data indicate that these drugs could be novel targets for cognitive improvement in MDD [183].

In conclusion, promising mechanistic experimental data indicate that manipulation of the gut microbiota with probiotics may open a new avenue for the prevention and treatment of MDD and associated comorbidities. These beneficial effects could attenuate metabolic endotoxemia. However, clinical trials have methodologi$\mathrm{cal}$ inconsistencies and variations in protocol. Therefore, the field awaits the design of large-scale and well-designed clinical trials.

\section{Prebiotics}

The Food and Agricultural Organization (FAO) of the United Nations define prebiotics as 'a nonviable food component that confers a health benefit on the host modulated by the microbiota' [184]. These 'functional foods' escape absorption in the small bowel and enter the colon, providing nutrients to specific bacteria, including Bifidobacteria and Lactobacilli. Several prebiotics are non-digestible carbohydrates: monosaccharides (e.g. fructose), disaccharides (e.g. lactose), oligosaccharides (e.g. fructo-oligosaccharides and galacto-oligosaccharides), and polyols, and the fermentable oligo- di- and monosaccharides and polyols or FODMAPs (e.g. inulin) [185]. A recent systematic review found that no RCT to date has evaluated prebiotics as a treatment strategy for MDD [186]. In addition, clinical trial data have been inconsistent for IBS [92]. Some positive signals have been observed for metabolic disorders, although clinical findings remain inconclusive [187].

\section{The Potential of Dietary Change to Benefit Gut}

Permeability and Disease Status

Diet quality profoundly influences immune function, systemic inflammation, and antioxidant capacity [for review, see 7 and 5]. Moreover, both short- and long-term diet is a key driver of microbiome composition and gut health. Individual gut microbiome enterotypes are linked to long-term dietary patterns [188], while in a key intervention study, only 2 weeks of dietary change had a profound impact on gut microbiota composition and markers of mucosal inflammation [189]. There are also exten- 
sive data from animal models to show that high-fat diets induce intestinal permeability and inflammation [for review, see 190]. Specifically, high-fat diets can alter the intestinal barrier structure and increase inflammation via a reduction of tight junction proteins [191]. However, key issues in the field relate to the lack of clarity regarding the potential differential impact of differing dietary fats as well as carbohydrate intake on gut health, immune and metabolic outcomes, and whether the impact of high-fat diets and similar paradigms is the same in humans as it is in animals. These issues are currently subject to intense investigation due to their likely relevance to public health and clinical approaches.

While it is well established that diet is of critical importance to the development of cardiovascular diseases, T2DM and obesity, it is increasingly clear that diet is also of substantial relevance to depression [192]. Indeed, two recent meta-analyses report that diet quality is inversely related to the likelihood of or risk for MDD [193], while emerging intervention data suggest a beneficial impact of dietary improvement on depression risk [194] and symptoms of depression [195]. In addition, preliminary prospective data indicate that the consumption of certain nutrients like red meat [196] and even milk [197] may confer a higher risk of developing depression. The recognition that diet is a key driver of gut health, as well as inflammation and oxidative stress, highlights the likely importance of the gut in mediating the association between diet and MDD [198] and points to the utility of targeting dietary quality to improve gut health and resulting disease states, including MDD [199, 200], IBS [201], and metabolic disorders $[202,203]$. For instance, alterations in the abundance of Roseburia, which has been noted in MDD, IBS, CFS, and obesity [10, 105, 204, 205], can be decreased by low-fat, high-complex carbohydrate diets [206].

\section{Conclusions}

The influence of commensal microbiota in the pathophysiology of MDD and its associated medical comorbidities is only beginning to be uncovered. Here we describe evidence that microbiota composition changes, bacterial translocation from a disrupted gut barrier, and metabolic endotoxemia may play a significant shared pathophysiological role in MDD and somatic comorbidities. The leaky gut (and resulting metabolic endotoxemia) in particular may contribute to immune activation, HPA axis imbalances, and O\&NS. This cascade of interacting events could be attenuated by several promising strategies targeting gut-related inflammation, including but not limited to dietary interventions and treatment with probiotics. However, large-scale, well-designed RCTs are awaited. An inherent limitation of these research efforts relies on the phenotypic heterogeneity of MDD and co-morbid diseases, and thus these mechanisms may distinctively contribute to the pathophysiology of different subsets of patients, who otherwise seem deceptively similar as they may share the same categorical diagnoses [207]. There is an unmet need in the field to translate these fascinating findings into preventative and therapeutic advances for MDD and related medical comorbidities.

\section{Acknowledgements}

C.A.K. is supported by a postdoctoral research fellowship from CAPES (Brazil). M.B. is supported by a National Health and Medical Research Council (NHMRC) Senior Principal Research Fellowship (1059660). I.G. has received a Juan Rodés research contract (JR15/00012) at the Instituto de Salud Carlos III, Spanish Ministry of Economy and Competiveness, Barcelona (Spain). E.V. thanks the Instituto de Salud Carlos III, Spanish Ministry of Economy and Competiveness, CIBERSAM (PI12/00912), the Grups Consolidats de Recerca 2014 (SGR 398), the Seventh European Framework Programme (ENBREC), and the Stanley Medical Research Institute for their support. A.F.C. is supported by a research fellowship award from CNPq (Brazil).

\section{Disclosure Statement}

R.S.M. has received grant/research support from the Stanley Medical Research Institute, the Brain and Behaviour Research Foundation, the National Institute of Mental Health, Eli Lilly, AstraZeneca, Lundbeck, Allergan, Takeda, Merck, Pfizer, JanssenOrtho, Bristol-Myers Squibb, Otsuka, and Johnson \& Johnson. M.B. has received research grants from the US National Institutes of Health (NIH), the Cooperative Research Centre, Simons Autism Foundation, the Cancer Council of Victoria, the Stanley Medical Research Foundation, the Medical Benefits Foundation (MBF), the NHMRC, Beyond Blue, Rotary Health, the Geelong Medical Research Foundation, Bristol-Myers Squibb, Eli Lilly, GlaxoSmithKline, the Meat and Livestock Board, Organon, Novartis, Mayne Pharma, Servier, and Woolworths; he has been a speaker for AstraZeneca, Bristol-Myers Squibb, Eli Lilly, GlaxoSmithKline, Janssen Cilag, Lundbeck, Merck, Pfizer, Sanofi Synthelabo, Servier, Solvay, and Wyeth and has served as consultant to AstraZeneca, Bioadvantex, Bristol-Myers Squibb, Eli Lilly, GlaxoSmithKline, Janssen Cilag, Lundbeck, Merck, and Servier. I.G. has received a Juan Rodés Contracts research grant (JR15/00012) at the Instituto de Salud Carlos III, Spanish Ministry of Economy and Competiveness, Barcelona, Spain; she has served as a consultant for Ferrer and has been a speaker for AstraZeneca, Ferrer, and Janssen Cilag. E.V. has received research grants, honoraria related to continuing
40

Psychother Psychosom 2017;86:31-46 DOI: $10.1159 / 000448957$
Slyepchenko et al. 
medical education, or consulting fees from AstraZeneca, Ferrer, Forest Research Institute, Gedeon Richter, GlaxoSmithKline, Janssen, Lundbeck, Otsuka, Pfizer, Sanofi -Aventis, Sunovion, Takeda, Centro para la Investigación Biomédica en Red de Salud Mental
(CIBERSAM), Grups Consolidats de Recerca 2014 (SGR 398), the Seventh European Framework Programme (ENBREC), and the Stanley Medical Research Institute. A.S., M.M., F.J., C.A.K., T.B., J.A.F., and A.F.C. have no conflicts of interest to declare.

\section{References}

1 Kiecolt-Glaser JK, Derry HM, Fagundes CP: Inflammation: depression fans the flames and feasts on the heat. Am J Psychiatry 2015;172: 1075-1091.

2 Lotrich FE: Inflammatory cytokine-associated depression. Brain Res 2015;1617:113-125.

3 Dowlati Y, Herrmann N, Swardfager W, Liu H, Sham L, Reim EK, Lanctôt KL: A metaanalysis of cytokines in major depression. Biol Psychiatry 2010;67:446-457.

4 Liu Y, Ho RC-M, Mak A: Interleukin (IL)-6, tumour necrosis factor alpha (TNF- $\alpha$ ) and soluble interleukin-2 receptors (sIL-2R) are elevated in patients with major depressive disorder: a meta-analysis and meta-regression. J Affect Disord 2012;139:230-239.

5 Moylan S, Berk M, Dean OM, Samuni Y, Williams LJ, O’Neil A, Hayley AC, Pasco JA, Anderson G, Jacka FN: Oxidative and nitrosative stress in depression: why so much stress? Neurosci Biobehav Rev 2014;45:46-62.

6 Moylan S, Maes M, Wray NR, Berk M: The neuroprogressive nature of major depressive disorder: pathways to disease evolution and resistance, and therapeutic implications. Mol Psychiatry 2013;18:595-606.

7 Berk M, Williams LJ, Jacka FN, O’Neil A, Pasco JA, Moylan S, Allen NB, Stuart AL, Hayley AC, Byrne ML, Maes M: So depression is an inflammatory disease, but where does the inflammation come from? BMC Med 2013;11: 200.

8 Benros ME, Waltoft BL, Nordentoft M, Ostergaard SD, Eaton WW, Krogh J, Mortensen PB: Autoimmune diseases and severe infections as risk factors for mood disorders: a nationwide study. JAMA Psychiatry 2013;70: 812-820.

9 Leonard B, Maes M: Mechanistic explanations how cell-mediated immune activation, inflammation and oxidative and nitrosative stress pathways and their sequels and concomitants play a role in the pathophysiology of unipolar depression. Neurosci Biobehav Rev 2012;36:764-785.

10 Zheng P, Zeng B, Zhou C, Liu M, Fang Z, Xu $X$, Zeng L, Chen J, Fan S, Du X, Zhang X, Yang D, Yang Y, Meng H, Li W, Melgiri ND, Licinio J, Wei H, Xie P: Gut microbiome remodeling induces depressive-like behaviors through a pathway mediated by the host's metabolism. Mol Psychiatry 2016;21:786-796.

11 Jiang $\mathrm{H}$, Ling Z, Zhang Y, Mao H, Ma Z, Yin Y, Wang W, Tang W, Tan Z, Shi J, Li L, Ruan B: Altered fecal microbiota composition in patients with major depressive disorder. Brain Behav Immun 2015;48:186-194.
12 Ogbonnaya ES, Clarke G, Shanahan F, Dinan TG, Cryan JF, O'Leary OF: Adult hippocampal neurogenesis is regulated by the microbiome. Biol Psychiatry 2015;78:e7-e9.

13 Foster JA, Neufeld K-AM: Gut-brain axis: how the microbiome influences anxiety and depression. Trends Neurosci 2013;36:305312.

14 Maes M, Kubera M, Leunis J-C: The gut-brain barrier in major depression: intestinal mucosal dysfunction with an increased translocation of LPS from Gram-negative enterobacteria (leaky gut) plays a role in the inflammatory pathophysiology of depression. Neuro Endocrinol Lett 2008;29:117-124.

15 Braniste V, Al-Asmakh M, Kowal C, Anuar F, Abbaspour A, Toth M, Korecka A, Bakocevic N, Ng LG, Kundu P, Gulyas B, Halldin C, Hultenby K, Nilsson H, Hebert H, Volpe BT, Diamond B, Pettersson S: The gut microbiota influences blood-brain barrier permeability in mice. Sci Transl Med 2014;6:263ra158.

16 Diehl GE, Longman RS, Zhang JX, Breart B, Galan C, Cuesta A, Schwab SR, Littman DR: Microbiota restricts trafficking of bacteria to mesenteric lymph nodes by $\mathrm{CX}_{3} \mathrm{CR} 1^{\text {hi }}$ cells. Nature 2013;494:116-120.

17 Whitehead WE, Palsson O, Jones KR: Systematic review of the comorbidity of irritable bowel syndrome with other disorders: What are the causes and implications? Gastroenterology 2002;122:1140-1156.

18 Nakao M, Nomura S, Yamanaka G, Kumano $\mathrm{H}$, Kuboki T: Assessment of patients by DSMIII-R and DSM-IV in a Japanese psychosomatic clinic. Psychother Psychosom 1998;67: 43-49.

19 Lane TJ, Manu P, Matthews DA: Depression and somatization in the chronic fatigue syndrome. Am J Med 1991;91:335-344.

20 Maes M, Twisk FN, Ringel K: Inflammatory and cell-mediated immune biomarkers in myalgic encephalomyelitis/chronic fatigue syndrome and depression: inflammatory markers are higher in myalgic encephalomyelitis/chronic fatigue syndrome than in depression. Psychother Psychosom 2012;81: 286-295.

21 Ali S, Stone M, Peters J, Davies M, Khunti K: The prevalence of co-morbid depression in adults with type 2 diabetes: a systematic review and meta-analysis. Diabet Med 2006;23: 1165-1173.
22 Lasserre AM, Glaus J, Vandeleur CL, MarquesVidal P, Vaucher J, Bastardot F, Waeber G, Vollenweider P, Preisig M: Depression with atypical features and increase in obesity, body mass index, waist circumference, and fat mass: a prospective, population-based study. JAMA Psychiatry 2014;71:880-888.

23 Dirmaier J, Watzke B, Koch U, Schulz H, Lehnert H, Pieper L, Wittchen HU: Diabetes in primary care: Prospective associations between depression, nonadherence and glycemic control. Psychother Psychosom 2010;79: 172-178.

24 Qin J, Li R, Raes J, Arumugam M, Burgdorf KS, Manichanh C, Nielsen T, Pons N, Levenez F, Yamada T: A human gut microbial gene catalogue established by metagenomic sequencing. Nature 2010;464:59-65.

25 Biasucci G, Rubini M, Riboni S, Morelli L, Bessi E, Retetangos C: Mode of delivery affects the bacterial community in the newborn gut. Early Hum Dev 2010;86(suppl 1):13-15.

26 Jakobsson HE, Abrahamsson TR, Jenmalm MC, Harris K, Quince C, Jernberg C, Bjorksten B, Engstrand L, Andersson AF: Decreased gut microbiota diversity, delayed Bacteroidetes colonisation and reduced Th1 responses in infants delivered by Caesarean section. Gut 2014;63:559-566.

27 Roger LC, Costabile A, Holland DT, Hoyles L, McCartney AL: Examination of faecal Bifidobacterium populations in breast- and formula-fed infants during the first 18 months of life. Microbiology 2010;156:3329-3341.

28 Palmer C, Bik EM, DiGiulio DB, Relman DA, Brown PO: Development of the human infant intestinal microbiota. PLoS Biol 2007;5:e177.

29 Kashtanova DA, Popenko AS, Tkacheva ON, Tyakht AB, Alexeev DG, Boytsov SA: Association between the gut microbiota and diet: fetal life, early childhood, and further life. $\mathrm{Nu}$ trition 2016;32:620-627.

30 Hildebrandt MA, Hoffmann C, Sherrill-Mix SA, Keilbaugh SA, Hamady M, Chen YY, Knight R, Ahima RS, Bushman F, Wu GD: High-fat diet determines the composition of the murine gut microbiome independently of obesity. Gastroenterology 2009;137:17161724.e1711-e1712.

31 Zhang C, Zhang M, Pang X, Zhao Y, Wang L, Zhao L: Structural resilience of the gut microbiota in adult mice under high-fat dietary perturbations. ISME J 2012;6:1848-1857.

32 Patterson E, Ryan PM, Cryan JF, Dinan TG, Ross RP, Fitzgerald GF, Stanton C: Gut microbiota, obesity and diabetes. Postgrad Med J 2016;92:286-300.
Role of Intestinal Dysbiosis and 'Leaky Gut' in the Pathophysiology of MDD
Psychother Psychosom 2017;86:31-46 DOI: $10.1159 / 000448957$ 
33 Everard A, Belzer C, Geurts L, Ouwerkerk JP, Druart C, Bindels LB, Guiot Y, Derrien M, Muccioli GG, Delzenne NM, de Vos WM, Cani PD: Cross-talk between Akkermansia muciniphila and intestinal epithelium controls diet-induced obesity. Proc Natl Acad Sci USA 2013;110:9066-9071.

34 Karlsson CL, Onnerfalt J, Xu J, Molin G, Ahrne S, Thorngren-Jerneck K: The microbiota of the gut in preschool children with normal and excessive body weight. Obesity (Silver Spring) 2012;20:2257-2261.

$35 \mathrm{Wu}$ M, McNulty NP, Rodionov DA, Khoroshkin MS, Griffin NW, Cheng J, Latreille P, Kerstetter RA, Terrapon N, Henrissat B, Osterman AL, Gordon JI: Genetic determinants of in vivo fitness and diet responsiveness in multiple human gut Bacteroides. Science 2015;350:aac5992.

36 Rakoff-Nahoum S, Paglino J, Eslami-Varzaneh F, Edberg S, Medzhitov R: Recognition of commensal microflora by Toll-like receptors is required for intestinal homeostasis. Cell 2004;118:229-241.

37 Boren J, Lee WN, Bassilian S, Centelles JJ, Lim S, Ahmed S, Boros LG, Cascante M: The stable isotope-based dynamic metabolic profile of butyrate-induced HT29 cell differentiation. J Biol Chem 2003;278:28395-28402.

38 Ogawa H, Rafiee P, Fisher PJ, Johnson NA, Otterson MF, Binion DG: Butyrate modulates gene and protein expression in human intestinal endothelial cells. Biochem Biophys Res Commun 2003;309:512-519.

39 Cryan JF, Dinan TG: Mind-altering microorganisms: the impact of the gut microbiota on brain and behaviour. Nat Rev Neurosci 2012; 13:701-712.

40 Dhiman RK: Gut microbiota and hepatic encephalopathy. Metab Brain Dis 2013;28:321326.

41 Ghanizadeh A, Berk M: Molecular hydrogen: an overview of its neurobiological effects and therapeutic potential for bipolar disorder and schizophrenia. Med Gas Res 2013;3:11.

42 NemeroffCB, Vale WW: The neurobiology of depression: inroads to treatment and new drug discovery. J Clin Psychiatry 2005;66:5.

43 Pariante CM: The glucocorticoid receptor: part of the solution or part of the problem? J Psychopharmacol 2006;20:79-84.

44 Morris G, Berk M: The many roads to mitochondrial dysfunction in neuroimmune and neuropsychiatric disorders. BMC Med 2015; 13:68.

45 Naseribafrouei A, Hestad K, Avershina E, Sekelja M, Linlokken A, Wilson R, Rudi K: Correlation between the human fecal microbiota and depression. Neurogastroenterol Motil 2014;26:1155-1162.

46 Berg RD, Garlington AW: Translocation of certain indigenous bacteria from the gastrointestinal tract to the mesenteric lymph nodes and other organs in a gnotobiotic mouse model. Infection and Immunity 1979;23:403411.
47 Wiest R, Garcia-Tsao G: Bacterial translocation (BT) in cirrhosis. Hepatology 2005;41: 422-433.

48 Maes M: The cytokine hypothesis of depression: inflammation, oxidative \& nitrosative stress (IO\&NS) and leaky gut as new targets for adjunctive treatments in depression. Neuro Endocrinol Lett 2008;29:287-291.

49 Grigoleit JS, Kullmann JS, Wolf OT, Hammes F, Wegner A, Jablonowski S, Engler H, Gizewski E, Oberbeck R, Schedlowski M: Dosedependent effects of endotoxin on neurobehavioral functions in humans. PLoS One 2011;6:e28330.

50 Baranyi A, Meinitzer A, Stepan A, Putz-Bankuti C, Breitenecker RJ, Stauber R, Kapfhammer HP, Rothenhausler HB: A biopsychosocial model of interferon- $\alpha$-induced depression in patients with chronic hepatitis c infection. Psychother Psychosom 2013;82: 332-340.

51 Mahajan S, Avasthi A, Grover S, Chawla YK: Incidence of depression in patients with chronic hepatitis $\mathrm{C}$ receiving combination therapy of pegylated interferon- $\alpha$ and ribavirin. Psychother Psychosom 2014;83:308-309.

52 Lucas K, Maes M: Role of the Toll-like receptor (TLR) radical cycle in chronic inflammation: possible treatments targeting the TLR4 pathway. Mol Neurobiol 2013;48:190-204.

53 Chan ED, Riches DW: IFN- $\gamma+$ LPS induction of iNOS is modulated by ERK, JNK/SAPK, and p38 MAPK in a mouse macrophage cell line. Am J Physiol Cell Physiol 2001; 280:C441-C450.

54 Wischmeyer PE: Glutamine: role in gut protection in critical illness. Curr Opin Clin Nutr Metab Care 2006;9:607-612.

55 Pai K, Sodhi A: Effect of cisplatin, rIFN-Y, LPS and MDP on release of $\mathrm{H}_{2} \mathrm{O}_{2}, \mathrm{O}_{2}$-and lysozyme from human monocytes in vitro. Indian J Exp Biol 1991;29:910-915.

56 Lewis C, McCarthy S, Lorenzen J, McGee J: Differential effects of LPS, IFN- $\gamma$ and TNF- $\alpha-$ on the secretion of lysozyme by individual human mononuclear phagocytes: relationship to cell maturity. Immunology 1990;69:402.

57 Maes M, Kubera M, Leunis JC, Berk M, Geffard $\mathrm{M}$, Bosmans $\mathrm{E}$ : In depression, bacterial translocation may drive inflammatory responses, oxidative and nitrosative stress (O\&NS), and autoimmune responses directed against O\&NS-damaged neoepitopes. Acta Psychiatr Scand 2013;127:344-354.

58 Clark JM, Diehl AM: Hepatic steatosis and type 2 diabetes mellitus. Curr Diab Rep 2002; 2:210-215.

59 Iovine NM, Pursnani S, Voldman A, Wasserman G, Blaser MJ, Weinrauch Y: Reactive nitrogen species contribute to innate host defense against Campylobacter jejuni. Infect Immun 2008;76:986-993.
60 Lin WN, Lin CC, Cheng HY, Yang CM: Regulation of cyclooxygenase-2 and cytosolic phospholipase A2 gene expression by lipopolysaccharide through the RNA-binding protein HUR: involvement of NADPH oxidase, reactive oxygen species and mitogenactivated protein kinases. Br J Pharmacol 2011;163:1691-1706.

61 Check J, Byrd CL, Menio J, Rippe RA, Hines IN, Wheeler MD: Src kinase participates in LPS-induced activation of NADPH oxidase. Mol Immunol 2010;47:756-762.

62 Peng T, Lu X, Feng Q: NADH oxidase signaling induces cyclooxygenase-2 expression during lipopolysaccharide stimulation in cardiomyocytes. FASEB J 2005;19:293-295.

63 Mehlhase J, Gieche J, Ullrich O, Sitte N, Grune T: LPS-induced protein oxidation and proteolysis in BV-2 microglial cells. IUBMB Life 2000;50:331-335.

64 Tyagi E, Agrawal R, Nath C, Shukla R: Effect of melatonin on neuroinflammation and acetylcholinesterase activity induced by LPS in rat brain. Eur J Pharmacol 2010;640:206-210.

65 Gawryluk JW, Wang JF, Andreazza AC, Shao L, Young LT: Decreased levels of glutathione, the major brain antioxidant, in post-mortem prefrontal cortex from patients with psychiatric disorders. Int J Neuropsychopharmacol 2011;14:123-130.

66 Sah SP, Tirkey N, Kuhad A, Chopra K: Effect of quercetin on lipopolysaccharide inducedsickness behavior and oxidative stress in rats. Indian J Pharmacol 2011;43:192.

67 Hall DM, Buettner GR, Oberley LW, Xu L, Matthes RD, Gisolfi CV: Mechanisms of circulatory and intestinal barrier dysfunction during whole body hyperthermia. Am J Physiol Heart Circ Physiol 2001;280:H509H521.

68 Iseme RA, McEvoy M, Kelly B, Agnew L, Attia J, Walker FR: Autoantibodies and depression: evidence for a causal link? Neurosci Biobehav Rev 2014;40:62-79.

69 Brandt LJ, Locke GR, Olden K, Quigley EM, Schoenfeld P, Schuster M, Talley N: An evidence-based approach to the management of irritable bowel syndrome in North America. Am J Gastroenterol 2002;97(suppl):S7-S26.

70 Drossman DA, Camilleri M, Mayer EA, Whitehead WE: AGA technical review on irritable bowel syndrome. Gastroenterology 2002;123:2108-2131.

71 Thompson W, Heaton K, Smyth G, Smyth C: Irritable bowel syndrome in general practice: prevalence, characteristics, and referral. Gut 2000;46:78-82.

72 Quigley E: Current concepts of the irritable bowel syndrome. Scand J Gastroenterol Suppl 2003;38:1-8.

73 Palsson OS, Drossman DA: Psychiatric and psychological dysfunction in irritable bowel syndrome and the role of psychological treatments. Gastroenterol Clin North Am 2005;34: 281-303. 
74 Whorwell P, Prior A, Colgan S: Hypnotherapy in severe irritable bowel syndrome: Further experience. Gut 1987;28:423-425.

75 Drossman DA, Whitehead WE, Toner BB, Diamant N, Hu YJ, Bangdiwala SI, Jia H: What determines severity among patients with painful functional bowel disorders? Am J Gastroenterol 2000;95:974-980.

76 Zhou Q, Zhang B, Verne GN: Intestinal membrane permeability and hypersensitivity in the irritable bowel syndrome. Pain 2009;146: 41-46.

77 Gecse K, Róka R, Séra T, Rosztóczy A, Annaházi A, Izbéki F, Nagy F, Molnár T, Szepes Z, Pávics L: Leaky gut in patients with diarrhea-predominant irritable bowel syndrome and inactive ulcerative colitis. Digestion 2011; 85:40-46.

78 Chadwick VS, Chen W, Shu D, Paulus B, Bethwaite P, Tie A, Wilson I: Activation of the mucosal immune system in irritable bowel syndrome. Gastroenterology 2002;122:17781783.

79 Collins S, Denou E, Verdu E, Bercik P: The putative role of the intestinal microbiota in the irritable bowel syndrome. Dig Liver Dis 2009;41:850-853.

80 Rajilić-Stojanović M, Biagi E, Heilig HG, Kajander K, Kekkonen RA, Tims S, de Vos WM: Global and deep molecular analysis of microbiota signatures in fecal samples from patients with irritable bowel syndrome. Gastroenterology 2011;141:1792-1801.

81 An S, Zong G, Wang Z, Shi J, Du H, Hu J: Expression of inducible nitric oxide synthase in mast cells contributes to the regulation of inflammatory cytokines in irritable bowel syndrome with diarrhea. Neurogastroenterol Motil 2016;28:1083-1093.

82 Liebregts T, Adam B, Bredack C, Röth A, Heinzel S, Lester S, Downie-Doyle S, Smith E, Drew $\mathrm{P}$, Talley NJ: Immune activation in patients with irritable bowel syndrome. Gastroenterology 2007;132:913-920.

83 Dinan TG, Quigley EM, Ahmed SM, Scully P, O'Brien S, O'Mahony L, O'Mahony S, Shanahan F, Keeling PN: Hypothalamic-pituitarygut axis dysregulation in irritable bowel syndrome: plasma cytokines as a potential biomarker? Gastroenterology 2006;130:304-311.

84 Reus V, Joseph M, Dallman M: ACTH levels after the dexamethasone suppression test in depression. N Engl J Med 1982;306:238.

85 Stokes PE: The potential role of excessive cortisol induced by HPA hyperfunction in the pathogenesis of depression. Eur Neuropsychopharmacol 1995;5:77-82.

86 Dlugosz A, Nowak P, D’Amato M, Mohammadian Kermani G, Nyström J, Abdurahman S, Lindberg G: Increased serum levels of lipopolysaccharide and antiflagellin antibodies in patients with diarrhea-predominant irritable bowel syndrome. Neurogastroenterol Motil 2015;27:1747-1754.
87 Öhman L, Isaksson S, Lindmark A-C, Posserud I, Stotzer P-O, Strid H, Sjövall H, Simrén $\mathrm{M}$ : T-cell activation in patients with irritable bowel syndrome. Am J Gastroenterol 2009;104:1205-1212.

88 Lindmark A, Isaksson S, Posserud I, Strid H, Sjövall H, Simrén M: B-cell activation in patients with irritable bowel syndrome (IBS). Neurogastroenterol Motil 2009;21:644e627.

89 O'Mahony L, McCarthy J, Kelly P, Hurley G, Luo F, Chen K, O'Sullivan GC, Kiely B, Collins JK, Shanahan F: Lactobacillus and Bifidobacterium in irritable bowel syndrome: symptom responses and relationship to cytokine profiles. Gastroenterology 2005;128: 541-551.

90 Prakash S, Rodes L, Coussa-Charley M, Tomaro-Duchesneau C: Gut microbiota: next frontier in understanding human health and development of biotherapeutics. Biologics 2011;5:71-86.

91 O’Mahony C, Scully P, O’Mahony D, Murphy S, O'Brien F, Lyons A, Sherlock G, MacSharry J, Kiely B, Shanahan F: Commensalinduced regulatory $\mathrm{T}$ cells mediate protection against pathogen-stimulated NF- $\kappa \mathrm{B}$ activation. PLoS Pathog 2008;4:e1000112.

92 Distrutti E, Monaldi L, Ricci P, Fiorucci S: Gut microbiota role in irritable bowel syndrome: new therapeutic strategies. World J Gastroenterol 2016;22:2219-2241.

93 Griffith JP, Zarrouf FA: A systematic review of chronic fatigue syndrome: don't assume it's depression. Prim Care Companion J Clin Psychiatry 2008;10:120.

94 Moylan S, Eyre HA, Berk M: Chronic fatigue syndrome: what is it and how to treat? Lancet Psychiatry 2015;2:1044-1045.

95 Janssens KA, Zijlema WL, Joustra ML, Rosmalen JG: Mood and anxiety disorders in chronic fatigue syndrome, fibromyalgia, and irritable bowel syndrome: results from the lifelines cohort study. Psychosom Med 2015; 77:449-457.

96 Fletcher MA, Zeng XR, Barnes Z, Levis S, Klimas NG: Plasma cytokines in women with chronic fatigue syndrome. J Transl Med 2009;7:96.

97 Lorusso L, Mikhaylova SV, Capelli E, Ferrari D, Ngonga GK, Ricevuti G: Immunological aspects of chronic fatigue syndrome. Autoimmun Rev 2009;8:287-291.

98 Bansal AS, Bradley AS, Bishop KN, KianiAlikhan S, Ford B: Chronic fatigue syndrome, the immune system and viral infection. Brain Behav Immun 2012;26:24-31.

99 Myhill S, Booth NE, McLaren-Howard J: Chronic fatigue syndrome and mitochondrial dysfunction. Int J Clin Exp Med 2009; 2:1-16.

100 Morris G, Maes M: Oxidative and nitrosative stress and immune-inflammatory pathways in patients with myalgic encephalomyelitis (ME)/chronic fatigue syndrome (CFS). Curr Neuropharmacol 2014; $12: 168-185$
101 Maes M, Mihaylova I, Kubera M, Uytterhoeven M, Vrydags N, Bosmans E: Increased 8-hydroxy-deoxyguanosine, a marker of oxidative damage to DNA, in major depression and myalgic encephalomyelitis/chronic fatigue syndrome. Neuro Endocrinol Lett 2009;30:715-722.

102 Maes M, Mihaylova I, Leunis J-C: Increased serum IgA and IgM against LPS of enterobacteria in chronic fatigue syndrome (CFS): indication for the involvement of Gramnegative enterobacteria in the etiology of CFS and for the presence of an increased gut-intestinal permeability. J Affect Disord 2007;99:237-240.

103 Maes M, Twisk FN, Kubera M, Ringel K, Leunis J-C, Geffard M: Increased IgA responses to the LPS of commensal bacteria is associated with inflammation and activation of cell-mediated immunity in chronic fatigue syndrome. J Affect Disord 2012;136: 909-917.

104 Logan AC, Rao AV, Irani D: Chronic fatigue syndrome: lactic acid bacteria may be of therapeutic value. Med Hypotheses 2003;60: 915-923.

105 Frémont M, Coomans D, Massart S, De Meirleir K: High-throughput $16 \mathrm{~S}$ rRNA gene sequencing reveals alterations of intestinal microbiota in myalgic encephalomyelitis/chronic fatigue syndrome patients. Anaerobe 2013;22:50-56.

106 Lakhan SE, Kirchgessner A: Gut inflammation in chronic fatigue syndrome. Nutr Metab (Lond) 2010;7:79.

107 Maes M, Ringel K, Kubera M, Anderson G, Morris G, Galecki P, Geffard M: In myalgic encephalomyelitis/chronic fatigue syndrome, increased autoimmune activity against 5-HT is associated with immuno-inflammatory pathways and bacterial translocation. J Affect Disord 2013;150:223-230.

108 Morris G, Berk M, Galecki P, Maes M: The emerging role of autoimmunity in myalgic encephalomyelitis/chronic fatigue syndrome (ME/CFS). Mol Neurobiol 2014;49. 741-756.

109 Maes M, Mihaylova I, Kubera M, Bosmans E: Not in the mind but in the cell: increased production of cyclo-oxygenase- 2 and inducible no synthase in chronic fatigue syndrome. Neuro Endocrinol Lett 2007;28:463-469.

110 Maes M, Mihaylova I, Leunis J-C: Chronic fatigue syndrome is accompanied by an IgM-related immune response directed against neoepitopes formed by oxidative or nitrosative damage to lipids and proteins. Neuro Endocrinol Lett 2006;27:615-622.

111 Maes M, Mihaylova I, Leunis J-C: Increased serum IgM antibodies directed against phosphatidyl inositol (PI) in chronic fatigue syndrome (CFS) and major depression: evidence that an IgM-mediated immune response against $\mathrm{PI}$ is one factor underpinning the comorbidity between both CFS and depression. Neuro Endocrinol Lett 2007;28: 861-867.
Role of Intestinal Dysbiosis and 'Leaky Gut' in the Pathophysiology of MDD
Psychother Psychosom 2017;86:31-46 DOI: $10.1159 / 000448957$ 
112 Gaab J, Rohleder N, Heitz V, Engert V, Schad T, Schürmeyer TH, Ehlert U: Stressinduced changes in LPS-induced pro-inflammatory cytokine production in chronic fatigue syndrome. Psychoneuroendocrinology 2005;30:188-198.

113 Hiles SA, Revesz D, Lamers F, Giltay E, Penninx BW: Bidirectional prospective associations of metabolic syndrome components with depression, anxiety, and antidepressant use. Depress Anxiety 2016;33:754-764.

114 Vancampfort D, Mitchell AJ, De Hert M, Sienaert P, Probst M, Buys R, Stubbs B: Type 2 diabetes in patients with major depressive disorder: a meta-analysis of prevalence estimates and predictors. Depress Anxiety 2015; 32:763-773.

115 Jacka FN, Sacks G, Berk M, Allender S: Food policies for physical and mental health. BMC Psychiatry 2014;14:132.

116 Dipnall JF, Pasco JA, Meyer D, Berk M, Williams LJ, Dodd S, Jacka FN: The association between dietary patterns, diabetes and depression. J Affect Disord 2015;174:215-224.

117 Liu CS, Carvalho AF, McIntyre RS: Towards a 'metabolic' subtype of major depressive disorder: shared pathophysiological mechanisms may contribute to cognitive dysfunction. CNS Neurol Disord Drug Targets 2014; 13:1693-1707.

118 Mujica-Parodi L, Renelique R, Taylor M: Higher body fat percentage is associated with increased cortisol reactivity and impaired cognitive resilience in response to acute emotional stress. Int J Obes (Lond) 2009;33:157-165.

119 Jones A, McMillan MR, Jones RW, Kowalik GT, Steeden JA, Deanfield JE, Pruessner JC, Taylor AM, Muthurangu V: Adiposity is associated with blunted cardiovascular, neuroendocrine and cognitive responses to acute mental stress. PLoS One 2012; 7:e39143.

120 Stetler C, Miller GE: Depression and hypothalamic-pituitary-adrenal activation: a quantitative summary of four decades of research. Psychosom Med 2011;73:114-126.

121 Esser N, Legrand-Poels S, Piette J, Scheen AJ, Paquot N: Inflammation as a link between obesity, metabolic syndrome and type 2 diabetes. Diabetes Res Clin Pract 2014;105: 141-150.

122 Debnath M, Agrawal S, Agrawal A, Dubey GP: Metaflammatory responses during obesity: pathomechanism and treatment. Obes Res Clin Pract 2016;10:103-113.

123 Pickup J, Mattock M, Chusney G, Burt D: NIDDM as a disease of the innate immune system: association of acute-phase reactants and interleukin-6 with metabolic syndrome X. Diabetologia 1997;40:1286-1292.

124 Herder C, Illig T, Rathmann W, Martin S, Haastert B, Müller-Scholze S, Holle R, Thorand $\mathrm{B}$, Koenig W, Wichmann $\mathrm{H}$ : Inflammation and type 2 diabetes: results from KORA Augsburg. Gesundheitswesen 2005; 67:S115-S121.
125 Choi J, Joseph L, Pilote L: Obesity and Creactive protein in various populations: a systematic review and meta-analysis. Obes Rev 2013;14:232-244.

126 Tsigos C, Kyrou I, Chala E, Tsapogas P, Stavridis JC, Raptis SA, Katsilambros N: Circulating tumor necrosis factor alpha concentrations are higher in abdominal versus peripheral obesity. Metabolism 1999;48: 1332-1335.

127 Spranger J, Kroke A, Möhlig M, Hoffmann $\mathrm{K}$, Bergmann MM, Ristow M, Boeing $\mathrm{H}$, Pfeiffer AF: Inflammatory cytokines and the risk to develop type 2 diabetes results of the prospective population-based European prospective investigation into cancer and nutrition (EPIC)-Potsdam study. Diabetes 2003;52:812-817.

128 Lee C, Adler A, Sandhu M, Sharp S, Forouhi N, Erqou S, Luben R, Bingham S, Khaw K, Wareham N: Association of C-reactive protein with type 2 diabetes: prospective analysis and meta-analysis. Diabetologia 2009;52: 1040-1047.

129 Monk JM, Hou TY, Turk HF, Weeks B, Wu C, McMurray DN, Chapkin RS: Dietary N-3 polyunsaturated fatty acids (PUFA) decrease obesity-associated Th17 cell-mediated inflammation during colitis. PLoS One 2012;7:e49739.

130 Slyepchenko A, Maes M, Kohler CA, Anderson G, Quevedo J, Alves GS, Berk M, Fernandes BS, Carvalho AF: T helper 17 cells may drive neuroprogression in major depressive disorder: proposal of an integrative model. Neurosci Biobehav Rev 2016;64:83100.

131 Kohlgruber A, Lynch L: Adipose tissue inflammation in the pathogenesis of type $2 \mathrm{di}$ abetes. Curr Diab Rep 2015;15:92.

132 Grant RW, Dixit VD: Adipose tissue as an immunological organ. Obesity (Silver Spring) 2015;23:512-518.

133 Nishikawa T, Edelstein D, Du XL, Yamagishi S-i, Matsumura T, Kaneda Y, Yorek MA, Beebe D, Oates PJ, Hammes H-P: Normalizing mitochondrial superoxide production blocks three pathways of hyperglycaemic damage. Nature 2000;404:787-790.

134 Valko M, Leibfritz D, Moncol J, Cronin MT, Mazur M, Telser J: Free radicals and antioxidants in normal physiological functions and human disease. Int J Biochem Cell Biol 2007;39:44-84.

135 Rupérez AI, Gil A, Aguilera CM: Genetics of oxidative stress in obesity. Int J Mol Sci 2014; 15:3118-3144.

136 VanderJagt DJ, Harrison JM, Ratliff DM, Hunsaker LA, Vander Jagt DL: Oxidative stress indices in IDDM subjects with and without long-term diabetic complications. Clin Biochem 2001;34:265-270.

137 Creely SJ, McTernan PG, Kusminski CM, Da Silva N, Khanolkar M, Evans M, Harte A, Kumar S: Lipopolysaccharide activates an innate immune system response in human adipose tissue in obesity and type 2 diabetes.
Am J Physiol Endocrinol Metab 2007; 292:E740-E747.

138 Gnauck A, Lentle RG, Kruger MC: The characteristics and function of bacterial lipopolysaccharides and their endotoxic potential in humans. Int Rev Immunol 2015:1-31.

139 Karlsson FH, Tremaroli V, Nookaew I, Bergstrom G, Behre CJ, Fagerberg B, Nielsen J, Backhed F: Gut metagenome in European women with normal, impaired and diabetic glucose control. Nature 2013;498:99-103.

140 Hersoug LG, Moller P, Loft S: Gut microbiota-derived lipopolysaccharide uptake and trafficking to adipose tissue: implications for inflammation and obesity. Obes Rev 2016; 17:297-312.

141 Harte AL, Varma MC, Tripathi G, McGee KC, Al-Daghri NM, Al-Attas OS, Sabico S, O'Hare JP, Ceriello A, Saravanan P, Kumar S, McTernan PG: High fat intake leads to acute postprandial exposure to circulating endotoxin in type 2 diabetic subjects. Diabetes Care 2012;35:375-382.

142 Ridaura VK, Faith JJ, Rey FE, Cheng J, Duncan AE, Kau AL, Griffin NW, Lombard V, Henrissat B, Bain JR, Muehlbauer MJ, Ilkayeva O, Semenkovich CF, Funai K, Hayashi DK, Lyle BJ, Martini MC, Ursell LK, Clemente JC, Van Treuren W, Walters WA, Knight R, Newgard CB, Heath AC, Gordon JI: Gut microbiota from twins discordant for obesity modulate metabolism in mice. Science 2013;341:1241214.

143 Naseribafrouei A, Hestad K, Avershina E, Sekelja M, Linløkken A, Wilson R, Rudi K Correlation between the human fecal microbiota and depression. Neurogastroenterol Motil 2014;26:1155-1162.

144 Ley RE, Bäckhed F, Turnbaugh P, Lozupone CA, Knight RD, Gordon JI: Obesity alters gut microbial ecology. Proc Natl Acad Sci USA 2005; 102:11070-11075.

145 Zhang X, Shen D, Fang Z, Jie Z, Qiu X, Zhang C, Chen Y, Ji L: Human gut microbiota changes reveal the progression of glucose intolerance. PLoS One 2013;8:e71108.

146 Brunoni AR, Lopes M, Fregni F: A systematic review and meta-analysis of clinical studies on major depression and BDNF levels: implications for the role of neuroplasticity in depression. Int J Neuropsychopharmacol 2008;11:1169-1180.

147 Yu YB, Zuo XL, Zhao QJ, Chen FX, Yang J, Dong YY, Wang P, Li YQ: Brain-derived neurotrophic factor contributes to abdominal pain in irritable bowel syndrome. Gut 2012;61:685-694.

148 Chen R, Liang FX, Moriya J, Yamakawa J, Sumino H, Kanda T, Takahashi T: Chronic fatigue syndrome and the central nervous system. J Int Med Res 2008;36:867-874.

149 Li B, Lang N, Cheng ZF: Serum levels of brain-derived neurotrophic factor are associated with diabetes risk, complications, and obesity: a cohort study from Chinese patients with type 2 diabetes. Mol Neurobiol 2015, Epub ahead of print. 
150 Sokol H, Pigneur B, Watterlot L, Lakhdari O, Bermúdez-Humarán LG, Gratadoux J-J, Blugeon S, Bridonneau C, Furet J-P, Corthier G: Faecalibacterium prausnitzii is an antiinflammatory commensal bacterium identified by gut microbiota analysis of Crohn disease patients. Proc Natl Acad Sci USA 2008; 105:16731-16736.

151 Duncan SH, Hold GL, Harmsen HJ, Stewart CS, Flint HJ: Growth requirements and fermentation products of Fusobacterium prausnitzii, and a proposal to reclassify it as Faecalibacterium prausnitzii gen. nov., comb. nov. Int J Syst Evol Microbiol 2002; 52:2141-2146.

152 Walker AW, Duncan SH, Leitch ECM, Child MW, Flint $\mathrm{HJ}$ : $\mathrm{pH}$ and peptide supply can radically alter bacterial populations and short-chain fatty acid ratios within microbial communities from the human colon. Appl Environ Microbiol 2005;71:36923700.

153 Macfarlane GT, Gibson GR: Carbohydrate fermentation, energy transduction and gas metabolism in the human large intestine; in Mackie RI, White BA (eds): Gastrointestinal Microbiology. New York, Springer, 1997, pp 269-318.

154 Lewis K, Lutgendorff F, Phan V, Söderholm JD, Sherman PM, McKay DM: Enhanced translocation of bacteria across metabolically stressed epithelia is reduced by butyrate. Inflamm Bowel Dis 2010;16:1138-1148.

155 Peng L, Li Z-R, Green RS, Holzman IR, Lin $\mathrm{J}$ : Butyrate enhances the intestinal barrier by facilitating tight junction assembly via activation of amp-activated protein kinase in Caco-2 cell monolayers. J Nutr 2009;139: 1619-1625.

156 Lin HV, Frassetto A, Kowalik EJ Jr, Nawrocki AR, Lu MM, Kosinski JR, Hubert JA, Szeto D, Yao X, Forrest G: Butyrate and propionate protect against diet-induced obesity and regulate gut hormones via free fatty acid receptor 3-independent mechanisms. PLoS One 2012;7:e35240.

157 Gérard P: Metabolism of cholesterol and bile acids by the gut microbiota. Digestion 2013; 3:14-24.

158 Dvorak K, Payne CM, Chavarria M, Ramsey L, Dvorakova B, Bernstein H, Holubec H, Sampliner RE, Guy N, Condon A: Bile acids in combination with low $\mathrm{pH}$ induce oxidative stress and oxidative DNA damage: relevance to the pathogenesis of Barrett's oesophagus. Gut 2007;56:763-771.

159 Clavel T, Duck W, Charrier C, Wenning M, Elson C, Haller D: Enterorhabdus caecimuris sp. nov., a member of the family Coriobacteriaceae isolated from a mouse model of spontaneous colitis, and emended description of the genus Enterorhabdus Clavel et al. 2009. Int J Syst Evol Microbiol 2010;60: 1527-1531.

160 Turnbaugh PJ: Microbiology: fat, bile and gut microbes. Nature 2012;487:47-48.
161 Ridlon JM, Kang D-J, Hylemon PB: Bile salt biotransformations by human intestinal bacteria. J Lipid Res 2006;47:241-259.

162 Song Y, Könönen E, Rautio M, Liu C, Bryk A, Eerola E, Finegold SM: Alistipes onderdonkii sp. nov. and Alistipes shahii sp. nov., of human origin. Int J Syst Evol Microbiol 2006;56:1985-1990.

163 Saulnier DM, Riehle K, Mistretta TA, Diaz MA, Mandal D, Raza S, Weidler EM, Qin X, Coarfa C, Milosavljevic A: Gastrointestinal microbiome signatures of pediatric patients with irritable bowel syndrome. Gastroenterology 2011;141:1782-1791.

164 David LA, Maurice CF, Carmody RN, Gootenberg DB, Button JE, Wolfe BE, Ling AV, Devlin AS, Varma Y, Fischbach MA: Diet rapidly and reproducibly alters the human gut microbiome. Nature 2014;505:559-563.

165 Elinav E, Strowig T, Kau AL, Henao-Mejia J, Thaiss CA, Booth CJ, Peaper DR, Bertin J, Eisenbarth SC, Gordon JI: NLRP6 inflammasome regulates colonic microbial ecology and risk for colitis. Cell 2011;145:745-757.

166 Duck LW, Walter MR, Novak J, Kelly D, Tomasi M, Cong Y, Elson CO: Isolation of flagellated bacteria implicated in Crohn's disease. Inflamm Bowel Dis 2007;13:11911201.

167 Mass M, Kubera M, Leunis J-C: The gutbrain barrier in major depression: intestinal mucosal dysfunction with an increased translocation of LPS from Gram-negative enterobacteria (leaky gut) plays a role in the inflammatory pathophysiology of depression. Neuro Endocrinol Lett 2008;29:117124.

168 Maes M, Kubera M, Leunis J-C, Berk M: Increased IgA and IgM responses against gut commensals in chronic depression: further evidence for increased bacterial translocation or leaky gut. J Affect Disord 2012;141: 55-62.

169 Fleissner CK, Huebel N, El-Bary MMA, Loh G, Klaus S, Blaut M: Absence of intestinal microbiota does not protect mice from dietinduced obesity. Br J Nutr 2010;104:919929.

170 Hill C, Guarner F, Reid G, Gibson GR, Merenstein DJ, Pot B, Morelli L, Canani RB, Flint HJ, Salminen S, Calder PC, Sanders ME: Expert consensus document. The International Scientific Association for Probiotics and Prebiotics consensus statement on the scope and appropriate use of the term probiotic. Nat Rev Gastroenterol Hepatol 2014;11:506-514.

171 Phillips JGP: The treatment of melancholia by the lactic acid bacillus. Br J Psychiatry 1910;56:422-NP.

172 Slyepchenko A, Carvalho AF, Cha DS, Kasper S, McIntyre RS: Gut emotions mechanisms of action of probiotics as novel therapeutic targets for depression and anxiety disorders. CNS Neurol Disord Drug Targets 2014;13:1770-1786.
173 Benton D, Williams C, Brown A: Impact of consuming a milk drink containing a probiotic on mood and cognition. Eur J Clin Nutr 2007;61:355-361.

174 Steenbergen L, Sellaro R, van Hemert S, Bosch JA, Colzato LS: A randomized controlled trial to test the effect of multispecies probiotics on cognitive reactivity to sad mood. Brain Behav Immun 2015;48:258264.

175 Didari T, Mozaffari S, Nikfar S, Abdollahi M: Effectiveness of probiotics in irritable bowel syndrome: updated systematic review with meta-analysis. World J Gastroenterol 2015;21:3072-3084.

176 Rao AV, Bested AC, Beaulne TM, Katzman MA, Iorio C, Berardi JM, Logan AC: A randomized, double-blind, placebo-controlled pilot study of a probiotic in emotional symptoms of chronic fatigue syndrome. Gut $\mathrm{Pa}$ thog 2009;1:6.

177 Cani PD, Possemiers S, Van de Wiele T, Guiot Y, Everard A, Rottier O, Geurts L, Naslain D, Neyrinck A, Lambert DM, Muccioli GG Delzenne NM: Changes in gut microbiota control inflammation in obese mice through a mechanism involving GLP-2-driven improvement of gut permeability. Gut 2009;58: 1091-1103.

178 Kobyliak N, Conte C, Cammarota G, Haley AP, Styriak I, Gaspar L, Fusek J, Rodrigo L, Kruzliak P: Probiotics in prevention and treatment of obesity: a critical view. Nutr Metab (Lond) 2016;13:14.

179 Sun J, Buys N: Effects of probiotics consumption on lowering lipids and CVD risk factors: a systematic review and meta-analysis of randomized controlled trials. Ann Med 2015;47:430-440.

180 Tazoe H, Otomo Y, Kaji I, Tanaka R, Karaki SI, Kuwahara A: Roles of short-chain fatty acids receptors, GPR41 and GPR43 on colonic functions. J Physiol Pharmacol 2008; 59(suppl 2):251-262.

181 Kimura I, Ozawa K, Inoue D, Imamura T, Kimura K, Maeda T, Terasawa K, Kashihara D, Hirano K, Tani T, Takahashi T, Miyauchi S, Shioi G, Inoue H, Tsujimoto G: The gut microbiota suppresses insulin-mediated fat accumulation via the short-chain fatty acid receptor GPR43. Nat Commun 2013;4:1829.

182 Lorenzi M, Ploug UJ, Vega G, Jansen JP: Liraglutide vs other daily GLP-1 analogues in people with type 2 diabetes: a network metaanalysis. Value Health 2015;18:A598-A599.

183 McIntyre RS, Powell AM, Kaidanovich-Beilin $\mathrm{O}$, Soczynska JK, Alsuwaidan M, Woldeyohannes HO, Kim AS, Gallaugher LA: The neuroprotective effects of GLP-1: possible treatments for cognitive deficits in individuals with mood disorders. Behav Brain Res 2013;237:164-171.

184 Pineiro M, Asp NG, Reid G, Macfarlane S, Morelli L, Brunser O, Tuohy K: FAO technical meeting on prebiotics. J Clin Gastroenterol 2008;42(suppl 3, pt 2):S156-S159.
Role of Intestinal Dysbiosis and 'Leaky Gut' in the Pathophysiology of MDD
Psychother Psychosom 2017;86:31-46 DOI: $10.1159 / 000448957$ 
185 Roberfroid M: Functional food concept and its application to prebiotics. Dig Liver Dis 2002;34(suppl 2):S105-S110.

186 Fond G, Boukouaci W, Chevalier G, Regnault A, Eberl G, Hamdani N, Dickerson F, Macgregor A, Boyer L, Dargel A, Oliveira J, Tamouza R, Leboyer M: The 'psychomicrobiotic': targeting microbiota in major psychiatric disorders: a systematic review. Pathol Biol (Paris) 2015;63:35-42.

187 Yoo JY, Kim SS: Probiotics and prebiotics: Present status and future perspectives on metabolic disorders. Nutrients 2016;8:173.

188 Wu GD, Chen J, Hoffmann C, Bittinger K, Chen YY, Keilbaugh SA, Bewtra M, Knights D, Walters WA, Knight R, Sinha R, Gilroy E, Gupta K, Baldassano R, Nessel L, Li H, Bushman FD, Lewis JD: Linking long-term dietary patterns with gut microbial enterotypes. Science 2011;334:105-108.

189 O'Keefe SJ, Li JV, Lahti L: Fat, fibre and cancer risk in African Americans and rural Africans. Nat Commun 2015;6:6342.

190 Murphy EA, Velazquez KT, Herbert KM: Influence of high-fat diet on gut microbiota: a driving force for chronic disease risk. Curr Opin Clin Nutr Metab Care 2015;18:515520.

191 Shen W, Wolf PG, Carbonero F, Zhong W, Reid T, Gaskins HR, McIntosh MK: Intestinal and systemic inflammatory responses are positively associated with sulfidogenic bacteria abundance in high-fat-fed male C57BL/6J mice. J Nutr 2014;144:1181-1187.

192 Sarris J, Logan AC, Akbaraly TN, Amminger GP, Balanza-Martinez V, Freeman MP, Hibbeln J, Matsuoka Y, Mischoulon D, Mizoue T, Nanri A, Nishi D, Ramsey D, Rucklidge JJ, Sanchez-Villegas A, Scholey A, Su KP, Jacka FN: Nutritional medicine as mainstream in psychiatry. Lancet Psychiatry 2015;2:271-274.
193 Lai JS, Hiles S, Bisquera A, Hure AJ, McEvoy M, Attia J: A systematic review and metaanalysis of dietary patterns and depression in community-dwelling adults. Am J Clin Nutr 2014;99:181-197.

194 Sanchez-Villegas A, Martinez-Gonzalez MA, Estruch R, Salas-Salvado J, Corella D, Covas MI, Aros F, Romaguera D, GomezGracia E, Lapetra J, Pinto X, Martinez JA, Lamuela-Raventos RM, Ros E, Gea A, Warnberg J, Serra-Majem L: Mediterranean dietary pattern and depression: the PREDIMED randomized trial. BMC Med 2013; 11:208.

195 Opie RS, O’Neil A, Itsiopoulos C, Jacka FN: The impact of whole-of-diet interventions on depression and anxiety: a systematic review of randomised controlled trials. Public Health Nutr 2015;18:2074-2093.

196 Jacka FN, Pasco JA, Williams LJ, Mann N, Hodge A, Brazionis L, Berk M: Red meat consumption and mood and anxiety disorders. Psychother Psychosom 2012;81:196198.

197 Pasco JA, Williams LJ, Brennan-Olsen SL, Berk M, Jacka FN: Milk consumption and the risk for incident major depressive disorder. Psychother Psychosom 2015;84:384386.

198 Dash S, Clarke G, Berk M, Jacka FN: The gut microbiome and diet in psychiatry: focus on depression. Curr Opin Psychiatry 2015;28: $1-6$.

199 Opie RS, Itsiopoulos C, Parletta N, SanchezVillegas A, Akbaraly TN, Ruusunen A, Jacka FN: Dietary recommendations for the prevention of depression. Nutr Neurosci 2015, Epub ahead of print.

200 O’Neil A, Berk M, Itsiopoulos C, Castle D, Opie R, Pizzinga J, Brazionis L, Hodge A, Mihalopoulos C, Chatterton ML, Dean OM, Jacka FN: A randomised, controlled trial of a dietary intervention for adults with major depression (the 'SMILES' trial): study protocol. BMC Psychiatry 2013;13:114.
201 Moayyedi P, Quigley EM, Lacy BE, Lembo AJ, Saito YA, Schiller LR, Soffer EE, Spiegel BM, Ford AC: The effect of dietary intervention on irritable bowel syndrome: a systematic review. Clin Transl Gastroenterol 2015; 6:e107.

202 Johnston BC, Kanters S, Bandayrel K, Wu P, Naji F, Siemieniuk RA, Ball GD, Busse JW, Thorlund K, Guyatt G, Jansen JP, Mills EJ: Comparison of weight loss among named diet programs in overweight and obese adults: a meta-analysis. JAMA 2014;312: 923-933.

203 Huang XL, Pan JH, Chen D, Chen J, Chen F, Hu TT: Efficacy of lifestyle interventions in patients with type 2 diabetes: a systematic review and meta-analysis. Eur J Intern Med 2016;27:37-47.

204 Kassinen A, Krogius-Kurikka L, Mäkivuokko H, Rinttilä T, Paulin L, Corander J, Malinen E, Apajalahti J, Palva A: The fecal microbiota of irritable bowel syndrome patients differs significantly from that of healthy subjects. Gastroenterology 2007; 133:24-33.

205 Isabel M-I, Lidia S-A, Pablo P-M, Cristina A-L, Fernando C, Francisco T, Isabel Q-OM Red wine polyphenols modulate fecal microbiota and reduce markers of the metabolic syndrome in obese patients. Food Funct 2016;7:1775-1787.

206 Haro C, Montes-Borrego M, Rangel-Zúñiga OA, Alcalá-Díaz JF, Gómez-Delgado F, Pérez-Martínez P, Delgado-Lista J, Quintana-Navarro GM, Tinahones FJ, Landa BB: Two healthy diets modulate gut microbial community improving insulin sensitivity in a human obese population. J Clin Endocrinol Metab 2015;101:233-242.

207 Fava GA, Guidi J, Grandi S, Hasler G: The missing link between clinical states and biomarkers in mental disorders. Psychother Psychosom 2014;83:136-141. 